\title{
EFFECTS OF CARBON NANOTUBE DEPOSITION TIME TO CARBON FIBER ON TENSILE LAP-SHEAR STRENGTH OF RESISTANCE WELDED CFRTP
}

\author{
KAZUTO TANAKA, KAZUHIRO AOTO \& TSUTAO KATAYAMA \\ Department of Biomedical Engineering, Doshisha University, Japan
}

\begin{abstract}
Carbon Nanotube (CNT) grafted carbon fibers were used for the heating element of resistance welding, and the effect of CNT deposition time at deposition temperature of $600^{\circ} \mathrm{C}$ on the tensile lap-shear strength of resistance welded CFRTP was evaluated. The longer the deposition time became, the longer the length of CNT became. The highest tensile lap-shear strength was obtained when CNT grafted carbon fibers grafted at the deposition time of 30 minutes were used for the heating element of resistance welding because it is reported that fiber matrix interfacial properties of the carbon fiber was improved by CNT deposition to the surface of carbon fiber. In the case of the CNT grafted carbon fibers grafted at the deposition time of 60 minutes, lower tensile lap-shear strength was obtained because of the poor impregnation of the resin into the carbon fiber due to the excess CNT on the carbon fibers. The length of CNT should be controlled to obtain good mechanical properties.

Keywords: thermoplastic resin, CFRTP, resistance welding, direct resistance heating, carbon nanotube, carbon nanotube grafted carbon fiber, chemical vaper deposition.
\end{abstract}

\section{INTRODUCTION}

In recent years, carbon dioxide emission regulations for motor vehicles have become stricter and stricter, and development of fuel efficiency improvement technology is urgently required. Carbon Fiber Reinforced Thermoplastics (CFRTP) are expected to be used as lightweight materials in mass-produced products from the point that CFRTP are superior in specific strength and specific stiffness [1]. Although CFRTP can be molded in the integrated complex structure, many joints exist in real production. Fastening methods such as bolts and rivets are often used in metal joining. As these methods need holes, which cause stress concentration and become the crack initiation, the joining methods without holes are expected to be developed [2], [3]. In the case of the welding of CFRTP, the melting properties with high temperature can be used because the thermoplastic resin is used for the matrix of CFRTP. Resistance welding technology has been developed for CFRTP, and the further improvement of bond strength is needed to reduce the bonding area. Carbon nanotube (CNT) is expected to be used as additive because of its remarkable physical, thermal and electric properties [4], [5]. Grafting CNT on the surface of carbon fibers was reported to improve the fiber matrix interfacial shear strength [6] and the resistance welding in which carbon fiber was used for heating elements was reported to increase bond strength [7]. Although the relationship between CNT deposition and tensile lap-shear strength were clarified, the effect of CNT deposition time has not been clarified yet.

In this study, CNT grafted carbon fiber was used for the heating element of resistance welding, and the effects of CNT deposition time of carbon fiber on the tensile lap-shear strength and the thermal properties of the bonding area of resistance welded CFRTP were evaluated. 


\section{MATERIALS AND EXPERIMENTAL PROCEDURES}

\subsection{Materials}

Unidirectional spread carbon fiber tow (Nippon Tokushu Fabric Inc., 90mm long and $12.5 \mathrm{~mm}$ wide) was used as a resistance welding heating element. Non-woven fabric (prototype, Kuraray Co., Ltd., Japan, $50 \mathrm{~g} / \mathrm{m}^{2}$ ) of Polyamide 6 (PA6, Ube Industries, Ltd., Japan) was the matrix of the bonding area.

CFRTP laminated materials were used for the materials to be welded, which were $100 \mathrm{~mm}$ long, $25 \mathrm{~mm}$ wide and $2 \mathrm{~mm}$ thick. CFRTP laminated plates were molded by press and injection hybrid molding machine (Satoh Machinery Works Co., Ltd., Japan). Non-crimp fabric $\left(\mathrm{NC}, 300 \mathrm{~g} / \mathrm{m}^{2},\left[0^{\circ} / 90^{\circ}\right]\right.$, Toho Tenax), which is PAN-based carbon fibers being stitched together by polyester thread, was used as the reinforcement with the stacking sequence of $\left[0^{\circ} / 90^{\circ}\right]_{3 \mathrm{~s}}$ and non-woven fabric of PA6, which is the same resin for the bonding area, was used for the matrix. As the molding condition: molding temperature was set at $270^{\circ} \mathrm{C}$, molding pressure was set at $2 \mathrm{MPa}$ and molding time was held for $3 \mathrm{~min}$ so that fiber volume fraction was $50 \%$.

\subsection{Method of CNT deposition}

The deposition of CNT on the surface of carbon fiber was carried out in Catalytic Chemical Vapor Deposition by a CVD apparatus (MPCVD-70, Microphase Co., Ltd., Japan), as shown in Fig. 1. Ni was used as the catalyst and ethanol as the carbon source. Ni was deposited on the surface of carbon fiber by electro Ni planting with the current of $0.3 \mathrm{~A}$ and the plating time of $1.5 \mathrm{~s}$ as shown in Fig. 2. Table 1 shows the conditions of the Ni plating bath (watt bath). The deposition condition of CNT is under vacuum at $600^{\circ} \mathrm{C}$ for 10,30 and $60 \mathrm{~min}$. These CNTs grafted carbon fibers were referred to as $10 \mathrm{~min}, 30 \mathrm{~min}$, and 60 min, respectively. The rate of the grafted CNT amount to the carbon fiber was measured as the weight increase rate of CNT. CNT grafted carbon fiber was observed with a scanning electron microscope (SEM, JSM-6390LT, JEOL, Japan) and length of CNT was defined as half of the length between the diameter of the outermost layer of the CNT grafted carbon fiber and the diameter of carbon fiber, as shown in eqn (1) below and Fig. 3.

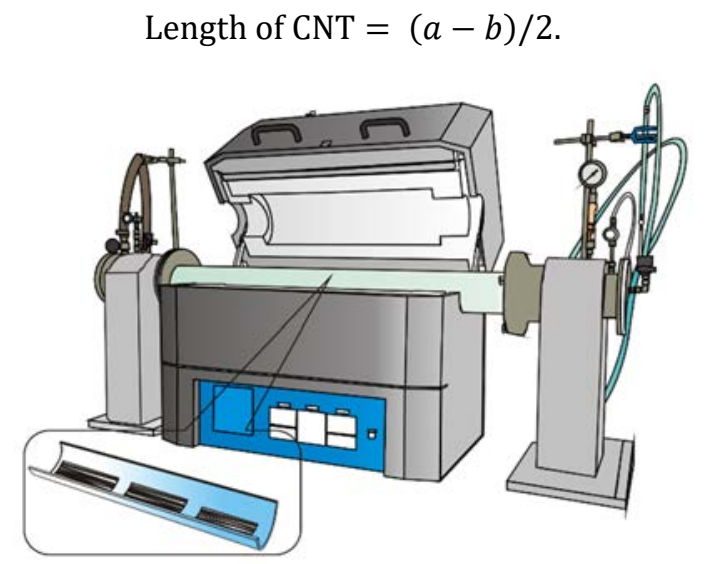

Figure 1: Schematic drawing of CVD apparatus for CNT grafting. 


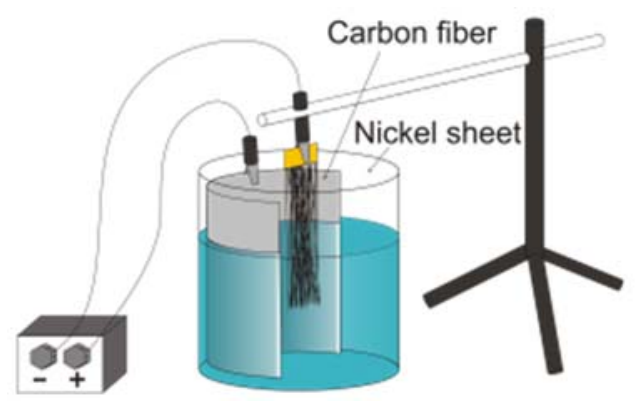

Figure 2: Schematic drawing of Ni plating method.

Table 1: Ni plating solution.

\begin{tabular}{|c|c|}
\hline Solution & Concentration $(\mathrm{g} / \mathrm{L})$ \\
\hline Nickel sulfate $\left(\mathrm{NiSO}_{4} \cdot \mathrm{H}_{2} \mathrm{O}\right)$ & 240 \\
\hline Nickel chloride $\left(\mathrm{NiCl}_{2} \cdot 6 \mathrm{H}_{2} \mathrm{O}\right)$ & 45 \\
\hline Boracic acid $\left(\mathrm{H}_{3} \mathrm{BO}_{4}\right)$ & 30 \\
\hline
\end{tabular}

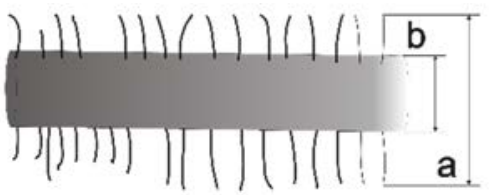

Figure 3: Schematic drawing of CNT grafted carbon fibers.

\subsection{Resistance welding methods and tensile lap-shear tests}

Fig. 4 shows the schematic drawing of the experimental step for resistance welding. Nonwoven fabric, carbon fiber as the heating element and non-woven fabric are placed between two CFRTP laminated materials. For the power supply to the heating element, a high frequency power supply unit (T162-6014AAH, Thamway Co., Ltd., Japan) and impedance converter (T010-6012A, Thamway Co., Ltd., Japan) at the frequency of $500 \mathrm{kHz}$ and the input power of $0.1 \mathrm{~kW}$ were used. After the melting of non-woven fabric of PA 6, welding pressure of $0.1 \mathrm{MPs}$ was applied for $3 \mathrm{~min}$.

Temperature distributions of the surface of the carbon fiber heated by resistance heating were observed by thermography (TVS-500EX, NEC, Japan). Tensile lap-shear strength tests were conducted by using a universal testing machine (AGX-100kN Xplus, SHIMADZU, Japan) as shown in Fig. 5.

\section{RESULT AND DISCUSSION}

\subsection{CNT deposition to surface of carbon fiber}

Fig. 6 shows the SEM images of CNT grafted carbon fiber at different deposition times. The length of CNT and rate of grafted CNT amount at different deposition times are shown in 
Fig. 7. The longer the deposition time became, the longer the length of CNT became. Considering the CNT grafting speed in each section of 0-10 min, 10-30 min, and 30-60 min as shown in Fig. 8, the speed drops rapidly and then gently increases to the last section. Similarly, for the speed of the rate of grafted CNT amount, it was higher as the section advances.

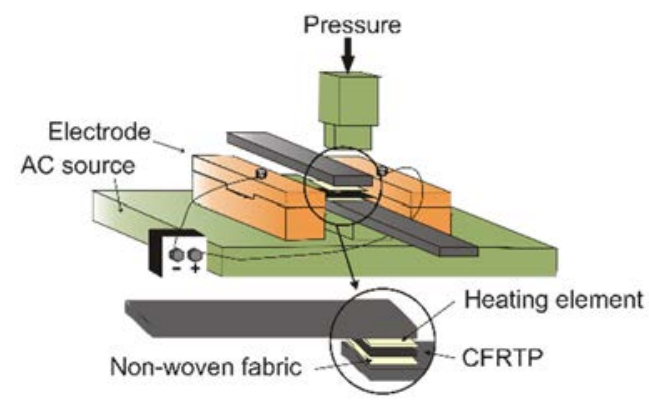

Figure 4: Schematic drawing of experimental step for resistance welding and lamination for welded part.

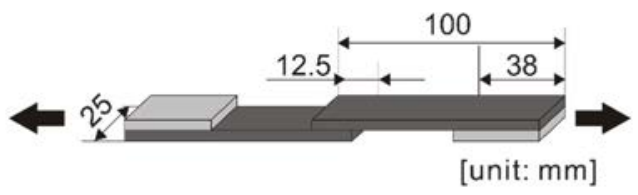

Figure 5: Schematic drawing of specimen of tension.

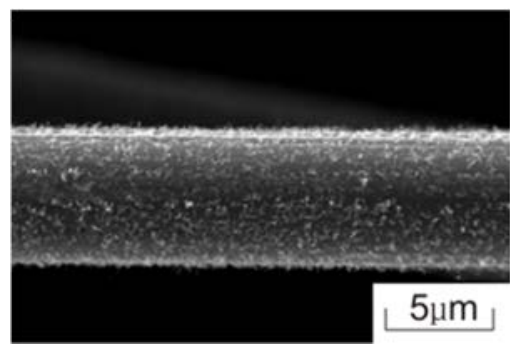

(a) $10 \mathrm{~min}$

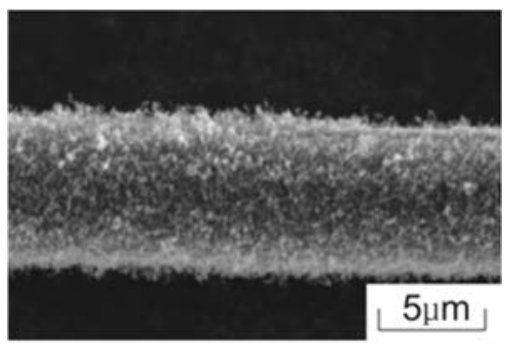

(b) $30 \mathrm{~min}$

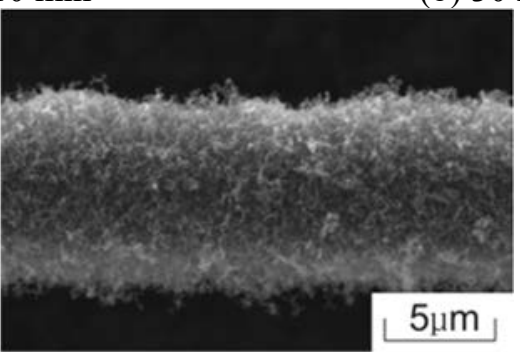

(c) $60 \mathrm{~min}$

Figure 6: SEM images of CNT grafted carbon fiber at different deposition times. 


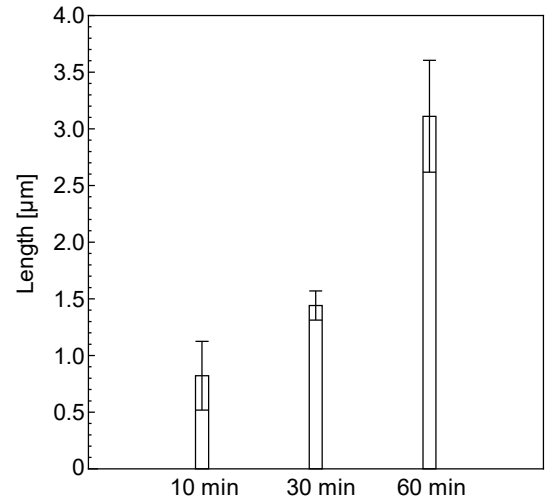

(a) Length of CNT

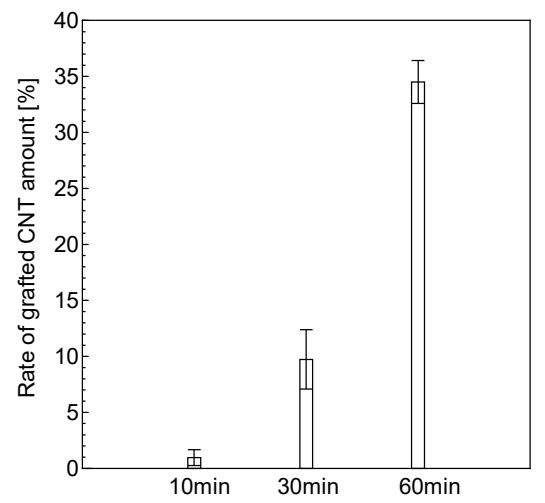

(b) Rate of grafted CNT amount

Figure 7: CNT deposition at different deposition time.

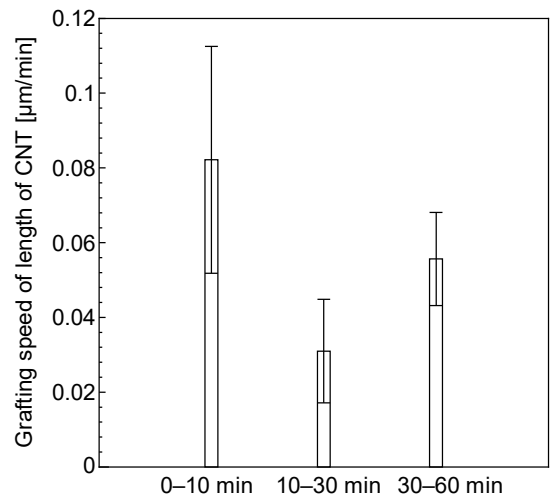

(a) Length of CNT

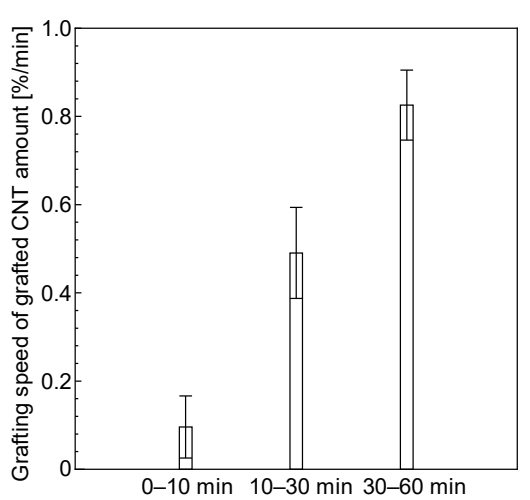

(b) Rate of grafted CNT amount

Figure 8: Grafting speed at different deposition time.

\subsection{Temperature distribution of carbon fiber}

Fig. 9 shows the thermography images of the surface of the carbon fiber heated by resistance heating. The temperature distribution is shown by the histogram in Fig. 10. The frequencies that are above $220^{\circ} \mathrm{C}$, which is the melting point of PA6 matrix, for $30 \mathrm{~min}$ are larger than that of as-received. CNT deposition can increase the higher temperature area above the melting point.

\subsection{Resistance welding and tensile lap-shear test}

Fig. 11 shows the cross-sections of the welding zone at different deposition times. For the specimens at the deposition temperatures of $10 \mathrm{~min}$ and $30 \mathrm{~min}$ no void was observed. On the contrary, for the specimen at the deposition temperature of 60 min many voids were observed at the interface between grafted carbon fibers and matrix. The impregnation of the resin to the interface was prevented because excess CNTs were grafted on the carbon fiber. 
Fig. 12 shows the tensile lap-shear strengths at different deposition times. The significant difference was not seen in as-received and $10 \mathrm{~min}$. The highest tensile lap-shear strength was obtained when CNT grafted carbon fibers grafted at the deposition time of 30 min were used for the heating element of resistance welding because it is reported that fiber matrix interfacial properties of the carbon fiber was improved by CNT deposition to the surface of carbon fiber [8]. In the case of the CNT grafted carbon fibers grafted at the deposition time of $60 \mathrm{~min}$, lower tensile lap-shear strength was obtained because of the poor impregnation of the resin into the carbon fiber due to the excess CNT on the carbon fibers. Fig. 13 shows the SEM observations of the fracture surfaces for as-received and $30 \mathrm{~min}$. For the specimen grafted for $30 \mathrm{~min}$, the resin impregnated into grafted CNTs on the surface of the carbon fiber.

\section{CONCLUSION}

CNT grafted carbon fibers were used for the heating element of resistance welding, and the effect of CNT deposition time at deposition temperature of $600{ }^{\circ} \mathrm{C}$ on the tensile lap-shear strength of resistance welded CFRTP was evaluated. The investigation yielded the following conclusions:

1. The longer the deposition time became, the longer the length of CNT became.

2. The highest tensile lap-shear strength was obtained when CNT grafted carbon fibers grafted at the deposition time for $30 \mathrm{~min}$ were used for the heating element of resistance welding. In the case of the CNT grafted carbon fibers grafted at the deposition time for $60 \mathrm{~min}$, lower tensile lap-shear strength was obtained because of the poor impregnation of the resin into the carbon fiber due to the excess CNT on the carbon fibers.

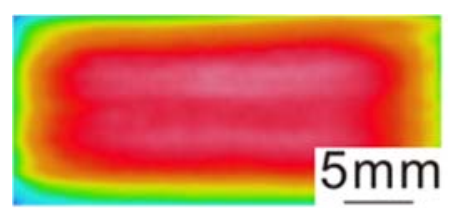

(a) As-received

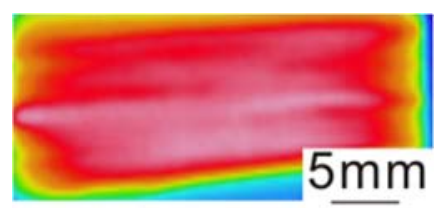

(b) $30 \mathrm{~min}$

Figure 9: Thermography images of carbon fiber heated by resistance heating.

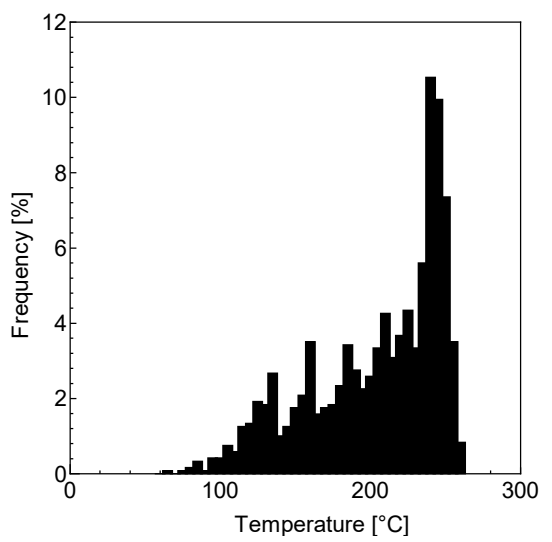

(a) as-received

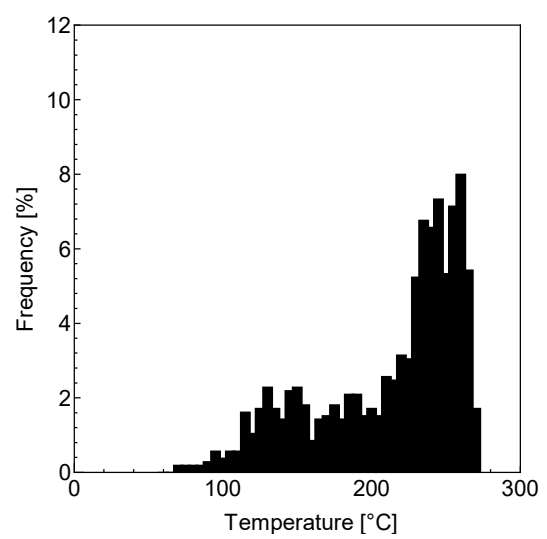

(b) $30 \mathrm{~min}$

Figure 10: Histogram of temperature distribution shown in Fig. 8. 


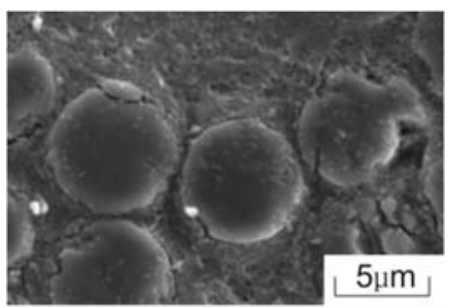

(a) $10 \mathrm{~min}$

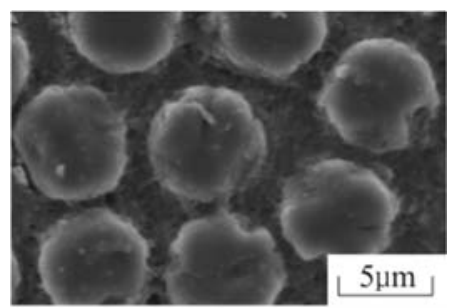

(b) $30 \mathrm{~min}$

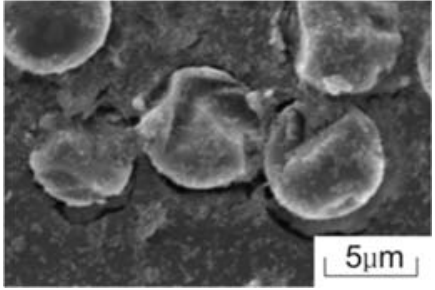

(c) $60 \mathrm{~min}$

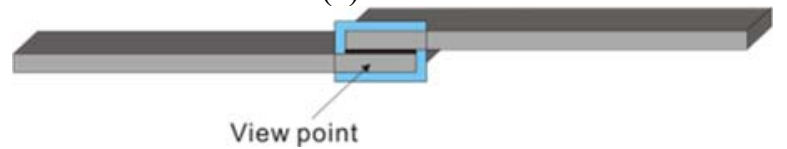

Figure 11: Cross-section of the welding zone.

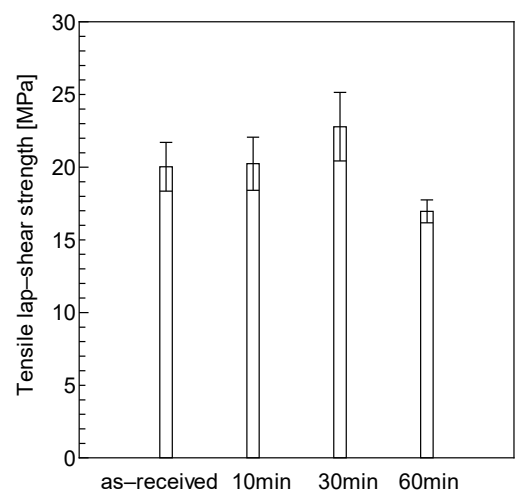

Figure 12: Tensile lap-shear strength at different deposition time.

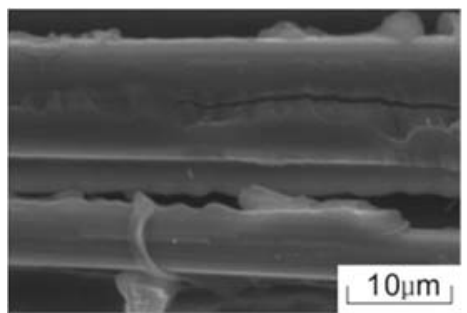

(a) as-received

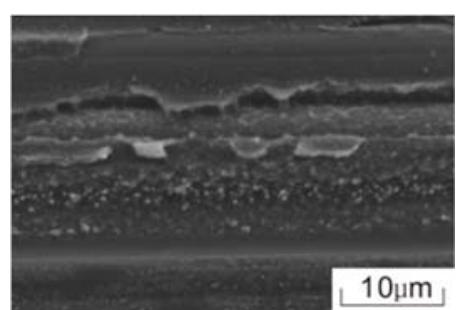

(b) $30 \mathrm{~min}$

Figure 13: Fracture surface of tensile lap-shear test. 


\section{ACKNOWLEDGEMENTS}

This work was partially supported by KAKENHI (Japan Society for the Promotion of Science, Grant-in-Aid for Scientific Research (B)) (26289011) and a research project on "Research and Development Center for Advanced Composite Materials" of Doshisha University and MEXT (the Ministry of Education, Culture, Sports, Science and Technology, Japan) - Supported Program for the Strategic Research Foundation at Private Universities, 2013-2017, the project S1311036.

\section{REFERENCES}

[1] Offringa, R., Thermoplastic composites-rapid processing applications. Composites: Part A, 27(4), pp. 329-336, 1996.

[2] Amancio-Filho, T.S. \& Santos, D.F.J., Joining of polymers and polymer-metal hybrid structures: Recent developments and trends. Polymer Engineering and Science, 49(8), pp. 1461-1476, 2009.

[3] Xiao, Y. \& Ishikawa, T., Bearing strength and failure behavior of bolted composite joints. Composites Science and Technology, 65(7-8), pp. 1022-1031, 2005.

[4] Sahooa, G.N., Ranab, S. \& Cho, W.J., Polymer nanocomposites based on functionalized carbon nanotubes. Progress in Polymer Science, 35(7), pp. 837-867, 2010.

[5] Al-Saleh H.M. \& Sundararaj, U., Review of the mechanical properties of carbon nanofiber/polymer composites. Composites Part A: Applied Science and Manufacturing, 42(12), pp. 2126-2142, 2011.

[6] Yumitori, S., Arao, Y., Tanaka, T., Naito, K., Tanaka, K. \& Katayama, T., Increasing the interfacial strength in carbon fiber/polypropylene composites by growing CNTs on the fibers. WIT Transactions on Modelling and Simulation, 55(10) pp. 275-284, 2013.

[7] Tanaka, K., Tanaka, Y.\& Katayama, T., Effect of Carbon Nanotube Grafting on Tensile Shear Strength of Resistance Welded CFRTP. Journal of Society of Materials Science, Japan, 65(10), pp. 727-732, 2016.

[8] Tanaka, K., Okumura, Y., Katayama, T. \& Morita, Y., Effect of carbon nanotubes deposition form on carbon fiber and polyamide resin interfacial strength. Journal of Society of Materials Science, Japan, 65(8), pp. 586-591, 2016. 